\title{
DIMERCAPROL IN THE PRE-NEUROLOGICAL STAGE OF WILSON'S DISEASE (HEPATOLENTICULAR DEGENERATION)
}

\author{
BY \\ C. G. WARNOCK and D. W. NEILL \\ From the Metabolic Department of the Institute of Pathology, Royal Victoria Hospital, Belfast
}

The pursuit of a solution to the enigma of Wilson's disease was stimulated and intensified by the discovery of its associated amino-aciduria by Uzman and Denny-Brown (1948) and the re-awakening of interest in the role of copper metabolism occasioned by the findings of Mandelbrote, Stanier, Thompson, and Thruston (1948), Cumings (1948, 1951), and subsequent workers.

Much that is important has thus been added to the existing knowledge of this disorder, and hopes of finding an effective means of controlling its progress have emerged from the encouraging response to treatment with dimercaprol $(2: 3$ dimercaptopropanol or BAL) in a number of cases, e.g., those of Cumings (1951), Denny-Brown and Porter (1951), Boudin, Pépin, and Calatchi (1952), and Streifler and Feldman (1953).

All these patients were individuals in whom the characteristic nervous symptoms were already well established and, in some instances, far advanced and of long duration. Nevertheless, administration of dimercaprol in appropriate dosage at regular intervals was followed by a lessening of tremor and rigidity with consequent improvement in motor functions.

Whether this measure of control can be maintained indefinitely in long-established cases remains to be seen, but the need for further trials of the drug in younger patients and earlier cases has been emphasized (Lancet, 1952).

The purpose of the present paper is to put on record a case in which this treatment was given before the onset of nervous symptoms. The progress of the patient since BAL was first used in May, 1949, will be described and the pre-neurological diagnosis of the disease discussed, together with the prospects of arresting its progress at this stage.

\section{Technical Procedures}

Copper estimations were made by the method of Eden and Green (1940) with the usual precautions against contamination of the specimens with extraneous copper and against other sources of error.

Urinary amino-acid excretion was investigated by twodimensional paper chromatography according to the method of Dent (1946). For total urinary aminonitrogen the procedure was that of Albanese and Irby (1944). Liver function tests were performed by standard techniques.

The BAL used was a $10 \% \mathrm{w} / \mathrm{v}$ solution in arachis oil, containing $20 \% \mathrm{w} / \mathrm{v}$ benzyl benzoate (supplied by Boots, Ltd.).

\section{Case History and Laboratory Data}

The patient, a boy aged 16 , is the only surviving member of a family of three children whose full clinical history has been described elsewhere (Warnock, 1952).

The parents are alive and well. The eldest child, a girl, died at age 11 from acute liver failure with jaundice and ascites. The second child, a boy, died at age 21, after a prolonged illness which began with ascites at 9 years and was followed by neurological troubles, first noticed at age 14, and eventually ending in gross extrapyramidal motor disorder, with contractures, dysphagia, and complete anarthria.

Clinically and anatomically the picture was that of classical Wilson's disease of the progressive type. Kayser-Fleischer rings were present in both corneae. No extended course of BAL was given to this patient but hypercupricuria was present (456 $\mu \mathrm{g}$./24 hours) and post-mortem copper levels in tissues were shown to be excessive both in the liver and in the various damaged areas of the brain. These findings were described fully at the time (Warnock, 1950). H. C., the present case, is the youngest member of the family.

At birth (1937) he was a normal infant and developed normally, but at age 3 the liver was found to be enlarged and tender and for almost a year before this he had been having frequent loose stools with occasional passage of blood and mucus. Throughout his childhood there was a more or less continuous tendency to looseness of the bowels, with spells of anorexia, pasty complexion. fluctuation in weight, and occasional pyrexia.

In March, 1948, at age 10 years and 8 months, faint Kayser-Fleischer rings were seen in both corneae. This was confirmed by slit-lamp microscopy. One month later there were signs of ascites, oedema of the lower 
extremities, and minimal jaundice. There was laboratory evidence of liver dysfunction (Table II) and a hypochromic microcytic anaemia with relative lymphocytosis. At this juncture he was admitted for a short time to the National Hospital, Queen Square, where Dr. E. A. Carmichael kindly confirmed the diagnosis of Wilson's disease.

Ascites disappeared in four weeks and has never returned. Slight haemorrhagic tendencies were evident and, for the next two or three years, there was recurrent epistaxis, small crops of petechiae, and excessive oozing from needle punctures. Blood coagulation properties were correspondingly deficient : blood platelets 70,200 per c.mm. ; prothrombin concentration $70 \%$; coagulation time, 11 minutes; bleeding time, 7 minutes; fragility normal.

A dietetic regime (high protein and carbohydrate, minimal fat) was instituted in May, 1948, and was supplemented with "hepovite" (Evans), Vitamins A, B-complex, C, and $\mathrm{K}$, as well as weekly injections of vitamin B $12(200 \mu \mathrm{g}$.). After a year on this routine laboratory tests still showed considerable derangement of liver function (Table II).

Copper--Preliminary copper investigations were carried out from January to March, 1949. Serum copper levels ranged from 165 to $296 \mu \mathrm{g}$. per $100 \mathrm{ml}$. in a series of 10 estimations, with a mean value of $200 \mu \mathrm{g}$. per 100 ml. (normal, 86-161 $\mu \mathrm{g}$. according to Cartwright, Huguley, Ashenbrucker, Fay, and Wintrobe, 1948). The plasma globulin content was raised during this time (Table II).

Urinary copper concentration, in a series of eight estimations during the same period, varied from 22 to $32 \mu \mathrm{g}$. per $100 \mathrm{ml}$. (normal, 0-14.7 $\mu \mathrm{g}$. per $100 \mathrm{ml}$., Porter, 1951) and the 24-hour output reached a maximum of $352 \mu \mathrm{g}$., as compared with normal standards of 10 to $68 \mu \mathrm{g}$. (Matthews, Milne, and Bell, 1952).

A single trial dose of dimercaprol $(200 \mathrm{mg}$.) raised the copper excretion from $253 \mu \mathrm{g}$. to $400 \mu \mathrm{g}$. in the succeeding 24 hours while the serum copper was elevated from 180 $\mu \mathrm{g}$. per $100 \mathrm{ml}$. before BAL to $280 \mu \mathrm{g}$. per $100 \mathrm{ml} .24$ hours later.

From May, 1949, onwards repeated courses of BAL have been given and for the past year this has been done at intervals of three months.

The dosage used is $400 \mathrm{mg}$. intramuscularly at fourhourly intervals on the first day, then at 12-hourly intervals for three days, and then once daily for a further four to six days. It has been found that pre-treatment levels of urinary copper are widely variable and are sometimes hardly above the possible limit of normal (Fig. 1).

But with this routine of treatment a phenomenal mobilization of copper can be produced and a high urinary output is maintained for some days after the last injection. For example, in April, 1952, urine was collected for three successive days before the beginning of treatment. The specimens were pooled, and a 500 ml. sample was taken for copper estimation. Similar portions were taken from the pooled 24-hour urines during the first three days of treatment and during the fourth, fifth, and sixth days after cessation of treatment. The findings were as follows (Table I).

TABLE I

URINARY COPPER EXCRETION

\begin{tabular}{|c|c|c|c|c|}
\hline & Normal & $\begin{array}{l}3 \text { Days } \\
\text { before: } \\
\text { BAL }\end{array}$ & $\begin{array}{c}\text { First } 3 \\
\text { Days of } \\
\text { Treatment }\end{array}$ & $\begin{array}{l}\text { 4th, 5th, and 6th } \\
\text { Days after End } \\
\text { of Treatment }\end{array}$ \\
\hline $\begin{array}{cr}\text { A verage } 24- \\
\text { hour } \\
(\mu \mathrm{g} .) & \text { output } \\
& .\end{array}$ & $10-68$ & 84 & 2,835 & 680 \\
\hline
\end{tabular}

Amino-aciduria.-An initial chromatographic analysis of the urine was done in July, 1951, at University College Hospital, by the courtesy of Dr. C. E. Dent. This showed slight but definitely increased quantities of glycine, serine, alanine, and glutamine, with a definite increase of tyrosine. There was also a very slightly raised output of cystine. Subsequently this was repeated by us on numerous occasions. The pattern regularly obtained is shown in Fig. 1, and indicates a generalized amino-aciduria.

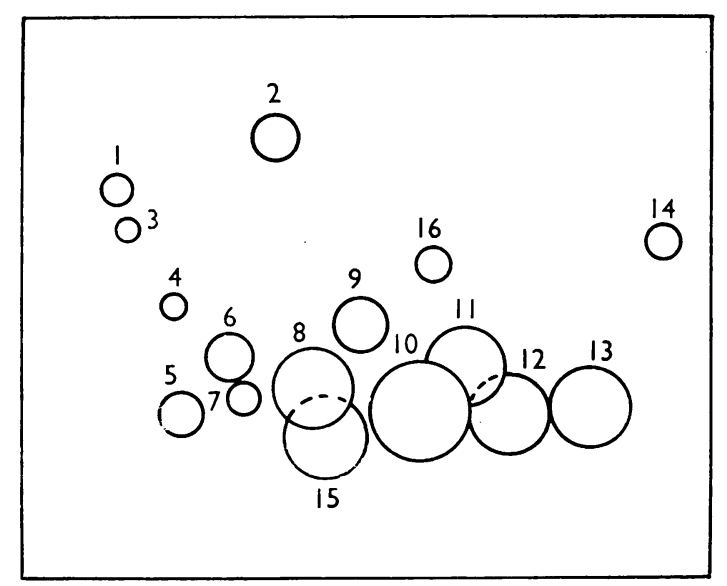

FIG. 1.-1. Phenylalanine. 2. Tyrosine. 3. Leucine. 4. Valine. 5. B-Aminoisobutyric acid. 6. a-Aminobutyric acid. 7. Histidine. 8. Alanine. 9. Threonine. 10. Glycine. 11. Serine. 12. Glutamic acid. 13. Aspartic acid. 14. Cysteic acid (from cystine). 15. Glutamine. 16. Taurine. The circle areas are proportional to the amounts of amino-acid in $25 \mu \mathrm{l}$. urine.

Chromatograms done on urines with a very high copper content (e.g., during the first three days of BAL treatment indicated in Table I) gave a similar amino-acid pattern with the exception of a more definite output of glutamic and aspartic acids.

Clinical Progress.-After the disappearance of ascites in 1948 the patient's general condition was satisfactory apart from the slight haemorrhagic tendencies noted above, and the periodic occurrence of short attacks of diarrhoea lasting a day or two at a time. These symptoms gradually became less and less obvious and for the 
past year they have been scarcely noticeable. No severe toxic reactions were observed in spite of the somewhat heavy dosage of BAL used. On the first day of a course, however, he has sometimes noticed a sensation of tingling and burning in the mouth and face, and in both hands. This is accompanied by marked conjunctival suffusion, and lacrimation. Tachycardia also occurs. All these phenomena disappear within an hour or so after the injection and as the course proceeds they become less and less noticeable.

Liver function tests have shown a steady trend for the better. Table II, which shows the serial results of these tests, indicates that the position is now quite satisfactory.

TABLE II

PROGRESS OF LIVER FUNCTION SINCE 1948

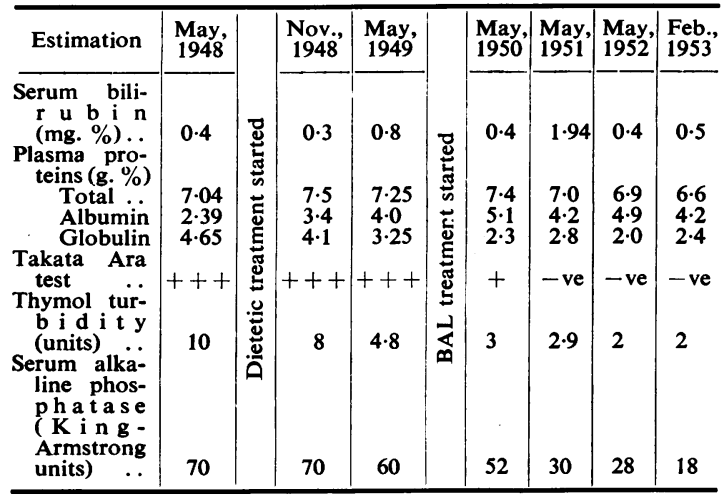

The liver itself remains palpable at two fingerbreadths below the costal margin. The edge of the organ is hard and apparently irregular. The spleen is slightly enlarged. Nervous signs and symptoms have remained completely absent. The patient is of good physique (height, $5 \mathrm{ft} .11$ in. ; weight, $70 \mathrm{~kg}$.) and sexual development is normal. Intellectually he is well above average.

The corneal pigment rings, however, have shown no signs of regression and are, in fact, much broader and deeper in colour than they were four years ago. Recent slit-lamp microscopy shows that there are signs of a second and inner pigment ring appearing in both corneae. This is a rare occurrence, but has been reported in at least one previous case, that of Froment, Bonnet, and Masson (1935).

\section{Discussion}

The exact significance of copper metabolism in the pathogenesis of Wilson's disease is still imperfectly understood but it is clear that, in certain cases, elimination of the metal in large quantities, as provoked by BAL, has been beneficial and that the ensuing clinical improvement was not coincidental.

It is also reasonably certain that copper begins to accumulate in the central nervous system before structural damage has occurred. In the case of Spillane, Keyser, and Parker (1952), for example, there were large deposits in the thalamus and cortex, although these areas were still anatomically intact, and the case described here shows that body stores of copper must be excessive long before outward manifestations of nervous disorder become apparent. Denny-Brown and Porter (1951) have therefore rightly drawn attention to the distinction between this "biochemical" lesion, which is potentially reversible, and the gross but irreversible structural lesions which characterize the cerebral pathology in classical Wilson's disease.

In so far as it is possible to envisage the degree of cerebral disorganization from the nature of the clinical picture, it is logical to suppose (as suggested by Denny Brown and Porter) that cases of the so-called " pseudo-sclerosis" variety, i.e., the more slowly progressive types, of later onset, and with tremor as the predominant feature, should respond best to treatment, since gross cerebral damage is often absent in such cases.

An example of the kind (Warnock, 1952, Case 4) recently observed here, however, presented no opportunity for treatment, as the patient (a married woman, aged 40) was admitted to hospital in a state of imminent hepatic failure, with jaundice and ascites, to which she rapidly succumbed.

Here, again, post-mortem enquiries revealed markedly excessive deposits of copper in the liver and brain, although the latter showed only minimal histological changes.

In the present case it was possible to begin treatment of the disorder while still in its purely hepatic phase, since the diagnosis was already apparent from the family history and the presence of corneal pigment rings.

In default of such confirmatory data the recognition of similar cases has hitherto presented insuperable difficulties. It is therefore worth while considering the diagnostic significance of biochemical data at this stage of the disease.

The existence of amino-aciduria in otherwise healthy siblings of proven cases has been reported by Uzman and Hood (1952) and indicates that the identification of potential victims in affected families should be possible. But the nature of the amino-aciduria in Wilson's disease is not sufficiently specific, in itself, to be absolutely diagnostic although it is easily demonstrable and displays a remarkably constant chromatographic pattern. Amongst the amino-acids detected we noted a repeatedly emphatic appearance of glutamic and aspartic acids in successive urinary chromatograms both in the present case and in that of the " pseudo-sclerosis" 
case mentioned above. A similar emphasis upon these two amino-acids was evident in the case of Boudin and others (1952), while Uzman and Hood (1952) have pointed out the marked predominance of peptides of glutamic and aspartic acids, accounting for 80 to $90 \%$ of the total urinary peptide content, in their cases.

Demonstration of the amino-acid excretion pattern by chromatographic analysis is of greater practical value than estimations of total urinary amino-nitrogen, for the latter is subject to considerable fluctuation; e.g., in the present case the total 24-hour urinary level of amino-nitrogen was at one period found to be within normal limits in three successive days, viz., $0.4 \mathrm{~g}$. $\mathrm{N}, 0.34 \mathrm{~g}$. $\mathrm{N}$, and 0.48 g. $\mathrm{N}$ respectively.

As regards copper findings, experience has proved that serum copper levels are of no diagnostic import, and they have been normal in some of the recorded cases (Brinton, 1947 ; Hood and Fagerberg, 1951 ; Spillane and others, 1952).

Matthews and others (1952) have emphasized that hypercupraemia is only likely in the presence of a raised serum globulin and this has, in fact, been true of cases in which high blood copper levels were found, including the case described here. Nevertheless, Scheinberg and Gitlin (1952) showed that the blood content of the copper-carrying globulin " caeruloplasmin" was consistently below normal in their cases of Wilson's disease. This may therefore prove to be a useful diagnostic index, but we have so far been unable to enquire into it here.

Urinary copper levels show periodic fluctuations during the course of the disease and a finding of excessive output cannot invariably be guaranteed at any given time, but repeated estimations must eventually reveal it.

The increase in cupricuria after BAL, on the other hand, is almost always significantly high; for example, in two-hour periods, Mandelbrote and others (1948) noted an elevation from $41.7 \mu \mathrm{g}$. to $109 \mu \mathrm{g}$. compared with $31.9 \mu \mathrm{g}$. rising to $61 \mu \mathrm{g}$. in normal subjects.

The minimum essential diagnostic criteria in doubtful cases would therefore consist in a gross " universal" amino-aciduria coincident with a high resting level of urinary copper, showing a very marked increase after BAL.

Since our own case satisfies these criteria and since this association of biochemical findings has not been observed in any other disorder, it may be claimed that an early diagnosis is possible on this basis alone.

Certainly it should be feasible by this means to differentiate the condition from other causes of hepatic cirrhosis in young subjects, and to avoid the erroneous label of "tuberculous peritonitis" when the disease presents with ascites, or of " Banti's disease" when splenomegaly and haemorrhagic phenomena are prominent, these latter being perhaps the commonest diagnostic pitfalls in the pre-neurological stage.

A rare, but not unknown, eventuality is the occurrence of osteoporosis and spontaneous fractures before the onset of nervous symptoms. This happened in the elder brother of our case, and the similarity of the resulting clinical picture (following closely upon ascites with anaemia) to that of the Fanconi syndrome was commented upon (Warnock, 1952). This comparison is heightened by the similarity of the amino-aciduria in the two diseases (Dent and Harris, 1951) but, although renal glycosuria is also occasionally present in Wilson's disease, the other biochemical changes of the Fanconi syndrome would serve to distinguish them. The present case exhibits no skeletal abnormality and the response to glucose tolerance tests was normal.

It is obvious that recognition before the onset of neurological troubles should enhance the prospect of successful treatment. Clinical manifestations of hepatic dysfunction are far more commonly seen at this time than at any later period in the evolution of the complaint and the early age at which they may begin is well illustrated here.

But, even when severe, they frequently subside and are succeeded by a quiescent period before nervous symptoms develop. This lull, which may be prolonged, is clearly the most opportune time for diagnosis and appropriate treatment. But the evaluation of the effects of treatment, in the absence of nervous symptoms, is peculiarly difficult for, as the clinical signs of liver dysfunction tend to disappear spontaneously in untreated cases, so does the laboratory evidence decline pari passu. Thus we hesitate to claim that the improvement in liver function shown by our case is entirely attributable to the treatment given. It may be noted, however, that whereas the liver function tests showed no impressive change in response to dietetic treatment, they began to show improvement after the first courses of dimercaprol. The failure of dietetic measures to control the progress of the disease was noted by Denny-Brown (1948) and his collaborators after a prolonged trial in a series of previously reported cases (Homburger and Kozol, 1946; Homburger, 1946).

A more significant detail here is the continued absence of nervous symptoms, and the clinical state of the patient contrasts favourably with that of his brother at the same age, in whom the first signs of 
nervous trouble appeared at age 14 and were well advanced at 16. In view of the tendency of the disease to pursue a closely similar course of evolution in members of the same family this can be regarded as a hopeful sign and may indicate that damage to the central nervous system has been delayed, though it is too soon to claim that it has been permanently averted.

The continued development of the KayserFleischer rings in this case contrasts with the observation of Denny-Brown and Porter (1951) who found regressive changes in the corneal pigment after BAL treatment. So far this alteration does not seem to have taken place in any other case so treated.

If the basis of this pigment is copper, as many authorities believe, its increased intensity in our case would appear to indicate that the metal is still accumulating in the body in spite of the treatment. Another possibility is that the mobilization of copper in the tissues by BAL may result in some redistribution of it, thus allowing more into the cornea.

The concentration of copper in the circulating blood has been shown to increase during BAL treatment (Cumings, 1951; Boudin and others, 1952), and the same thing was observed in our case. But the excess must be accounted for by quantities of the metal chemically linked to dimercaprol, and that this could be retained in the cornea seems unlikely. At all events, the present state of the Kayser-Fleischer rings in this case provides no clue to the ultimate prognosis and, from what has been stated above, it is evident that time will prove to be the only reliable arbiter of successful treatment.

Four years have now elapsed since the beginning of BAL therapy in this patient who was, in fact, one of the earliest cases to have it and is, to the best of our knowledge, the first to be subjected to a prolonged trial of dimercaprol in the absence of nervous symptoms.

It is for these reasons, and to draw attention to the special problems which such cases may be expected to raise, that it is presented here.

\section{Summary}

A pre-neurological case of Wilson's disease is described and its progress during four years of treatment with dimercaprol is recorded.

Almost all evidence of hepatic dysfunction has disappeared and nervous symptoms are still absent.

Clinical and diagnostic problems associated with the disease at this stage are discussed.

The biochemical investigations were carried out in the Metabolic Department of the Institute of Pathology, Royal Victoria Hospital, Belfast, by kind permission of Dr. J. A. Smyth.

Amongst others to whom we are indebted we especially wish to mention the following: Dr. C. E. Dent, University College Hospital, for his helpful interest; Dr. J. N. Cumings, National Hospital, Queen Square, for advice on copper investigations and the use of BAL at a time when it had not yet been tried out in this disease; Dr. Beatrice Lynn for slit lamp microscopy ; and Mr. John Coulter (chief technician of the laboratory) for his invaluable assistance throughout.

\section{REFERENCES}

Albanese, A. A., and Irby, V. (1944). J. biol. Chem., 153, 583. Boudin, G., Pépin, B., and Calatchi (1952). Rev. neural., Paris, $87,271$.

Brinton, D. (1947). Proc. roy. Soc. Med., 40, 556.

Cartwright, G. E., Huguley, C. M., Ashenbrucker, H., Fay, J., and Wintrobe, M. M. (1948). Blood, 3, 501 .

Cumings, J. N. (1948). Brain, 71, 410.

(1951). Ibid., 74, 10.

Denny-Brown, D.(1948). Personal communication

- , and Porter, H. (1951). New Engl. J. Med., 245, 917.

Dent, C. E. (1946). Lancet, 2, 637.

- and Harris, H. (1951). Ann. Eugen., Camb., 16, 60.

Eden, A., and Green, H. H. (1940). Biochem. J., 34, 1202

Froment, J., Bonnet, P., and Masson, R. (1935). J. med. Lyon, 16, 393.

Homburger, F. (1946). New Engl. J. Med., 234, 683.

-, and Kozol, H. L. (1946). J. Amer. med. Ass., 130, 6.

Hood, B., and Fagerberg, S. E. (1951). Acta med. scand., 140, 374

Lancet (1952). Annotation, 1, 199.

Mandelbrote, B. M., Stanier, M. W., Thompson, R. H. S., and Thruston, M. N. (1948). Brain, 71, 212.

Matthews, W. B., Milne, M. D., and Bell, M. (1952). Quart. J. Med., n.s., 21, 425 .

Porter, H. (1951). Arch. Biochem. Biophys., 31, 262.

Scheinberg, I. H., and Gitlin, D. (1952). Science, 116, 484

Spillane, J. D., Keyser, J. W., and Parker, R. A. (1952). J. clin. Path., 5, 16.

Streifler, M., and Feldman, S. (1953). Arch. Neurol. Psychiat., Chicago, 69, 84.

Uzman, L., and Denny-Brown, D. (1948). Amer. J. med. Sci.,

215, 599.

Warnock, C. G. (1950). M.D. Thesis. The Queen's University, Belfast. (Unpublished).

(1952). Ulster med. J., 21, 155. 